\title{
Application of HPLC with ELSD Detection for the Assessment of Azelaic Acid Impurities in Liposomal Formulation
}

\author{
Stanislaw Han, ${ }^{1}$ Katarzyna Karlowicz-Bodalska, ${ }^{1}$ Dorota Szura, ${ }^{2}$ \\ Lukasz Ozimek, ${ }^{2}$ and Witold Musial ${ }^{3}$ \\ ${ }^{1}$ Department of Industrial Pharmacy, Wroclaw Medical University, Borowska Street 211A, 50-556 Wroclaw, Poland \\ ${ }^{2}$ Research and Development Center NOVASOME, Olsztyńska Street 5, 51-423 Wroclaw, Poland \\ ${ }^{3}$ Department of Physical Chemistry, Wroclaw Medical University, Borowska Street 211A, 50-556 Wroclaw, Poland
}

Correspondence should be addressed to Witold Musial; witold.musial@gmail.com

Received 30 July 2013; Accepted 11 September 2013

Academic Editors: A. Concheiro and Y. Fiamegos

Copyright (c) 2013 Stanislaw Han et al. This is an open access article distributed under the Creative Commons Attribution License, which permits unrestricted use, distribution, and reproduction in any medium, provided the original work is properly cited.

\begin{abstract}
In the course of research and development of a new pharmaceutical formulation of azelaic acid in the liposomal form, we developed a rapid and accurate method for the detection of impurities using high-performance liquid chromatography. A chromatographic column from Merck (Purospher Star RP C18, 250-4 mm $(5 \mu \mathrm{m})$ was used in the assay, and the mobile phase gradient consisted of three phases: A-methanol : water $(5: 95)+1.5 \%$ (v/v) acetic acid; B-water : methanol $(5: 95)+1.5 \%(\mathrm{v} / \mathrm{v})$ acetic acid; and Cchloroform. Detection of the impurities and the active substance was performed by an evaporative light-scattering detector. The method was validated for selectivity, system precision, method precision, limit of detection, and response rates. The proposed method can be used to detect impurities in the liposomal formulation of azelaic acid. The method enables separation of azelaic acid from the identified and unidentified impurities and from the excipients used in the drug form.
\end{abstract}

\section{Introduction}

Chemically, azelaic acid is a saturated dicarboxylic acid, also known as nonanedioic acid. Under natural conditions, azelaic acid forms on human skin from the interaction of nonanoic acid with Malassezia furfur, a microbe of the dermal bacterial flora. The azelaic acid structure is shown in Figure 1.

Azelaic acid is a relatively new therapeutic substance used in the treatment of acne. The therapeutic use of azelaic acid in the form of a $15 \%$ cream has been practiced for the past two decades. Azelaic acid has several pharmacological effects: antibacterial, keratolytic, bleaching, and metabolic [1]. The antibacterial activity is based primarily on its biocidal activity against Propionibacterium acnes and Staphylococcus epidermidis. The inhibitory effect on the 5-alpha-reductase reduces the formation of dihydrotestosterone, normally synthesised in the skin from testosterone: in effect, a reduction of the lipogenesis process in the affected tissue is observed $[2,3]$.

The separation and quantitative determination of the content of carboxylic acids, especially dicarboxylic acids, by chromatography have been relevant issues in analytical chemistry since the 1950s and were initially accomplished using simple systems, such as paper-based chromatography or chromatography with simple silica gel columns $[4,5]$. New methods proposed for the determination of azelaic acid and other dicarboxylic acids include advanced LC, HPLC, and GC with the respective detection systems. One of the first fast GC qualitative and quantitative analyses of fatty acids was described by Metcalfe and Schmitz-it relies on the derivatisation of fatty acids to methyl esters with a solution of boron trifluoride in methanol [6].

GC combined with the derivatisation of fatty acids to methyl esters has been used to determine the amount of azelaic acid in the oil paints of old Flemish masters [7]. A similar method has been applied for evaluating the composition of wall paints [8]. Modified GC-MS has been used to study the composition of medieval and Renaissance Florentine paintings originally containing proteins and fatty acids, including azelaic acid [9]. GC-MS has also been used to determine the content of azelaic acid in samples of air from 


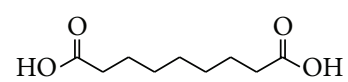

FIGURE 1: Molecule of azelaic acid.

the natural environment $[10,11]$. An interesting GC method for evaluating the content of azelaic acid in the natural aquatic environment was offered by Pusvaskiene et al.; they used simultaneous derivatisation and dispersive microextraction using immiscible liquids (acetone and carbon tetrachloride), whereas ethyl chloroformate was used as a reagent for derivatisation [12]. The GC method has been intensively developed due to the difficulties in providing sufficiently precise determinations [13]. The azelaic acid content in tobacco leaves has been determined by modified GC-MS using methyl derivatives and by means of solid-phase microextraction (solid-phase microextraction, SPME) [14].

Attempts to assess azelaic acid in very complex analytical matrices, for example, in biological samples of human or vegetable origin, have been made using both HPLC [15] and GC-MS methods [16]. Mansour and Ibrahiem solved the problem of simultaneous quantification of azelaic acid and benzoic acid by using isocratic, reversed-phase HPLC [17]. Ferioli et al. proposed a method for determining azelaic acid by reversed-phase HPLC (RP-HPLC) using precolumn derivatisation followed by solid-phase extraction (SPE) of a complex matrix (a pharmaceutical preparation); the derivatisation ensures detection of the active substance, which does not have a chromophore [18]. In another RPHPLC method with a fluorescence detector, 2-bromoacetyl6-methoxynaphthalene was used as a fluorescent marker in an aqueous micellar solution and in acetonitrile. This method enabled simultaneous determination of the azelaic acid and meglutol, that is, 3-hydroxy-3-methylglutaryl acid, in one sample [19]. In a complex mixture of carboxylic and dicarboxylic acids and amino acids, azelaic acid was assessed as a derivative of isobutyl chloroformate in GC, coupled with positive chemical ionisation MS (GC-MS-PCI) [20].

Preparation of the samples in GC methods is time consuming and requires considerable work. In addition, during the methylation of the sample, aggressive methylating reagents shorten the life of the chromatographic column and the integrity of the autosampler needle in a gas chromatograph. The mentioned disturbances cause frequent replacement of the column and needle and are associated with additional costs and time. Due to the obstacles encountered when using GC methods for dicarboxylic acid assessments, we decided to develop an alternative method to determine the limit of azelaic acid impurities in the final product-the liposomal form of azelaic acid. According to the available references, it is possible to use an evaporative light-scattering detector (ELSD) within an HPLC device to assess the fatty acids [21, 22].

In the last decade, the HPLC-ELSD method was intensively developed to analyse pharmaceutical products; the influence of the melting point and volatility of the analytes on the method efficiency was evaluated $[23,24]$. Fries et al. attempted to use HPLC-ELSD to determine metabolites of 7ethoxycoumarin from hepatocyte cell culture [25]. The use of an ELSD in the study of the lipid composition of the mixtures was introduced at the beginning of the last century [26]. Some authors compared the method of detection by refractive index (refractive index detector, RID) with the ELSD method [27]. The HPLC-ELSD method for the determination of fatty acids was suggested by Bravi and colleagues for examining vegetable oils: soybean, rice, pumpkin, and algae [21]. Fatty acids have been determined by HPLC-ELSD in raw herbal materials in the presence of saponins [22]. Wurst et al. have used this method for the determination of ethyl esters of fatty acids in the hair of alcohol-addicted persons [28]. The HPLCELSD method for the evaluation of serum lipids has been optimised and validated, which allows the separation and simultaneous determination of the following components in plasma: cholesterol esters, triglycerides, free cholesterol, and phosphatidylcholine [29]. The extremely complex composition of cow's milk was studied by the HPLC-ELSD method for the evaluation of phospholipids and sphingolipids that were structured in the globular form [30].

The aim of this study was to develop an analytical method that enables quick and reliable determination of the presence of azelaic acid impurities above a certain limit in new liposomal pharmaceutical formulations using HPLC with an ELSD.

\section{Materials and Equipment}

The following materials and equipment were used: Agilent Technologies 1200 HPLC; methanol (for HPLC); water (for HPLC); chloroform (for HPLC); $40 \%$ acetic acid (for HPLC); column: Merck, Purospher Star RP, C18, 250-4 mm, $(5 \mu \mathrm{m})$; reference sample of azelaic acid (AA, Fluka, serial number S38946); reference samples of impurities: pentanedioic acid (I1, Aldrich, serial number: S44628), hexanedioic acid (I2, Aldrich, serial number: 07128AJ), heptanedioic acid (I3, Aldrich, serial number: S68231), octanedioic acid (I4, Aldrich, serial number: S47580), decanedioic acid (I5, Aldrich, serial number: S69314), undecanedioic acid (I6, Aldrich, serial number: 1365985), dodecanedioic acid (I7, Aldrich, serial number: MKBB0577), tridecanedioic acid (I8, Aldrich, serial number: 03106JG), tetradecanedioic acid, and I9 (Aldrich, serial number: S29979); $0.20 \mu \mathrm{m}$ syringe filters; $2 \mathrm{~mL}$ syringes; and HPLC probes.

\section{Conditions of the HPLC Analysis}

In the course of the analysis, we used an Agilent Technologies 1200 high-performance liquid chromatograph with a Merck column (Purospher Star RP, C18, 250-4 mm (5 $\mu \mathrm{m})$ ). Detection was performed by an ELSD. As a mobile phase, the following mixtures were used: A-methanol: water $(5: 95)$ $+1.5 \%(\mathrm{v} / \mathrm{v})$ acetic acid, B-water : methanol $(5: 95)+1.5 \%$ (v/v) acetic acid, C-chloroform.

Detection was performed using an ELSD. The flow of the mobile phase in the HPLC was $1.0 \mathrm{~mL} / \mathrm{min}$, the column temperature was $30^{\circ} \mathrm{C}$, and the injection volume was $50 \mu \mathrm{L}$. 


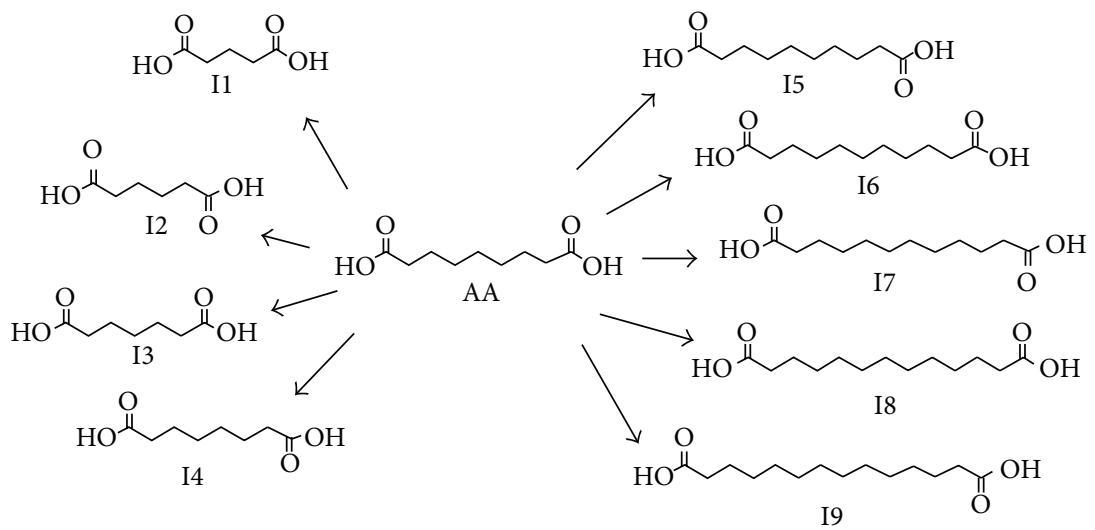

FIGURE 2: Known impurities of azelaic acid (AA)—dicarboxylic acids (I1-I9).

The temperature of the nebulisation within the ELSD was set at $40^{\circ} \mathrm{C}$, whereas the flow of inert gas-nitrogen-inside the detector was set at $1.6 \mathrm{l} / \mathrm{min}$.

\section{Sample Preparation}

The following samples were tested: the liposomal form of azelaic acid prepared without active substance (placebo, L), the liposomal form of azelaic acid with active substance (LA), a reference sample of azelaic acid (AA), and reference samples of identified impurities (I1-I9) that were prepared by dissolving them in mobile phase B (water: methanol $(5: 95)$ $+1.5 \%(\mathrm{v} / \mathrm{v})$ acetic acid). During the evaluation of the assay method, solutions of individual impurities (I1-I9) and a mixture of standards of known impurities (I1: I9) were used for comparison.

\section{Results and Discussion}

Impurities in the liposomal formulations of azelaic acid were determined by HPLC against a reference solution prepared by dilution of the test samples. According to the available references, the known major impurities of azelaic acid are homologous dicarboxylic acids, as shown in Figure 2.

Development of the new test method using HPLC with an ELSD included validation of the method with the following parameters: the selectivity of the method, the impact of stress factors, the precision of the system, the precision of the method, the limit of detection, and the response factors. However, validation of an assay of the limit of impurities must also include specificity, detection limit, and robustness. Validation of the method was carried out in accordance with the ICH requirements [31]. Limits were adopted on the basis of the available references and were valid for pharmaceutical products during the period of the study $[32,33]$.

5.1. Selectivity/Specificity. To determine the selectivity of the developed test method, the following evaluations of chromatograms were performed: evaluation of $\mathrm{L}$, evaluation of LA, evaluation of AA, evaluation of the solutions of known impurities of azelaic acid I1 to I9, evaluation of a mixture of

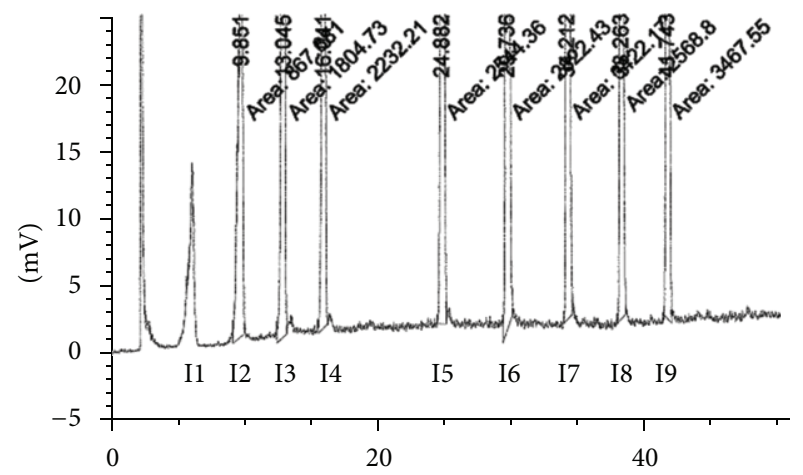

FIgURE 3: Chromatogram of the assessed known impurities, I1-I9.

impurities of azelaic acid (I1 : I9), and evaluation of the mobile phase (B).

During the analytical procedure, the retention times of the impurities of azelaic acid were confirmed. The expected shortest retention time, $R_{\mathrm{Ta}}$, was specified on the basis of the assessment of the glutaric acid standard solution, corresponding to the impurity I1. The longest expected retention time, $R_{\mathrm{Tb}}$, was specified according to the data from the evaluation of a standard solution of tetradecanedioic acid, I9. All the chromatograms obtained were analysed by taking into account only the peaks satisfying the condition tested: $R_{\mathrm{Ta}} \leq R_{\mathrm{Tx}} \leq R_{\mathrm{Tb}}$. An example of a chromatogram of the considered mixture of impurities is presented in Figure 3.

As a result of the evaluation of the chromatogram of the mobile phase, it was found that there was no peak observed at the retention time characteristic of the impurities of azelaic acid. In addition, in the chromatogram of the placebo sample (L), no peaks resulting from known impurities were observed. However, two peaks were observed and were defined as $\mathrm{P} 1$ and $\mathrm{P} 2$, with retention times of $R_{t 1}=12.2 \mathrm{~min}$ and $R_{t 2}=18.3 \mathrm{~min}$, respectively; the impurities $\mathrm{P} 1$ and $\mathrm{P} 2$ were identified as impurities that did not originate from the azelaic acid. The chromatogram of the sample solution-the liposomal dosage form of azelaic acid (LA) - consisted of the main peak of azelaic acid with an average retention time of 


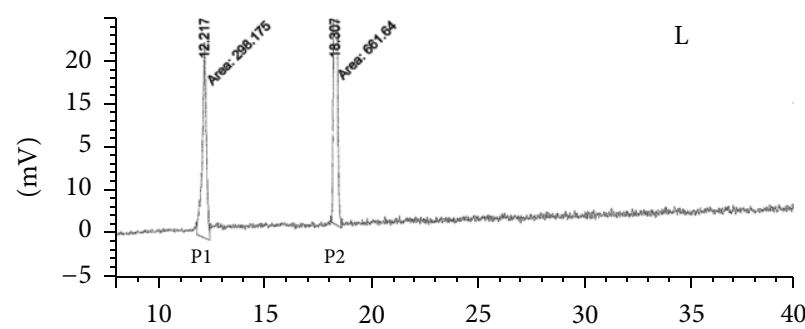

(a)

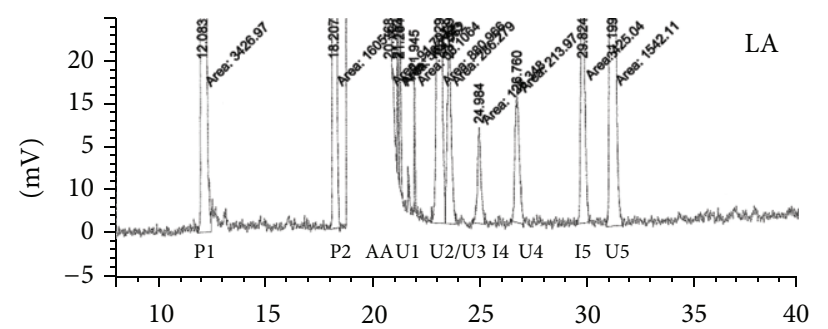

(b)

FIGURE 4: Chromatograms of HPLC-ELSD assessments: L-placebo, liposomal form of azelaic acid without the active substance; LAliposomal form of azelaic acid; P1 and P2-impurities originating from the components of the formulation; AA-azelaic acid; I4 and I5identified impurities; and U1-U5-unidentified impurities observed in the liposomal formulation of the azelaic acid.

$20.0 \mathrm{~min}$. Two peaks were identified as similar to the peaks from the placebo sample (L) with average retention times of $12.2 \mathrm{~min}$ and $18.3 \mathrm{~min}$, respectively. The following peaks were also observed: a peak from identified impurity I4 with an average retention time of $24.9 \mathrm{~min}$, a peak from identified impurity I5 with an average retention time of $29.8 \mathrm{~min}$, and the peaks of five unidentified impurities-U1, U2, U3, U4, and U5-with average retention times of $21.9 \mathrm{~min}, 23.1 \mathrm{~min}$, $23.6 \mathrm{~min}, 26.8 \mathrm{~min}$, and $31.2 \mathrm{~min}$, respectively. Sample chromatograms of the placebo test sample (L) and the test sample (LA) are summarised in Figure 4.

Chromatograms of HPLC-ELSD assessments: Lplacebo, liposomal form of azelaic acid without the active substance; LA-liposomal form of azelaic acid; P1 and $\mathrm{P} 2$-impurities originating from the components of the formulation; AA-azelaic acid; I4 and I5-identified impurities; and U1-U5-unidentified impurities observed in the liposomal formulation of the azelaic acid.

In the course of the subsequent analyses, we demonstrated that an unidentified impurity, U5, with an average retention time of 26.8 min occurs in the samples and that its concentration increases over time in the course of successive injections of the same solution. Because of this observation, we advise that the sample tested must be prepared immediately prior to injection.

5.2. Stress Tests. The following stress factors were applied to the standard solution of azelaic acid (AA) and to the sample of the liposomal formulation of azelaic acid (LA) during the 24-hour evaluation: $0.1 \mathrm{M} \mathrm{HCl}, 0.1 \mathrm{M} \mathrm{NaOH}, 3 \%$ solution of $\mathrm{H}_{2} \mathrm{O}_{2}$, the presence of water, and exposure to light. Furthermore, the effect of a temperature of $60^{\circ} \mathrm{C}$ for $1 \mathrm{~h}$ and the effect of sonication for 30 minutes on the sample were evaluated. On the chromatograms obtained from the analysis, it was found that the peak of the unidentified impurity U4 with an average retention time of $26.8 \mathrm{~min}$ appears in the standard samples of azelaic acid (AA) and in the sample (LA) in all stress conditions. Surprisingly, the peak for the unidentified impurity U5 with an average retention time of 31.2 occurs only in the LA sample. Based on this study, it can be concluded that the method meets the acceptance criteria for the determination of selectivity; the proposed test method is selective.
5.3. Precision of the System. The precision of the system was determined by an 8-fold analysis of the solution of nine azelaic acid impurities (I1: I9). The results of the chromatographic system precision are shown in Table 1 . The acceptance criterion was a value of $\mathrm{RSD}<5.3 \%$.

5.4. Precision of the Method. To check the precision of the analysis method, we assessed eight test samples and the reference solutions prepared according to the analytical procedure described above. In each of the samples, the location and size of the areas of the peaks of impurities were determined: two identified (I5 and I6) and three unidentified (U2, U5, and U6) with observed retention times of $23.1 \mathrm{~min}$, $26.8 \mathrm{~min}$, and $31.3 \mathrm{~min}$. In this method, the determination of impurities of the active substance is not required to match the determination of the precision method; however, the test was performed to better understand the conditions of the test. Table 2 summarises the results of determinations of the impurities in the test samples, along with the standard deviation and the relative standard deviation. The amount of impurities was reported as a fraction of the azelaic acid content. The results show the high precision of the test method for key impurities found in the liposomal form of azelaic acid.

5.5. Limit of Detection. The limit of detection for all impurities of azelaic acid was specified as a value corresponding to the triplicate value of noise in the placebo sample (L). The chromatograms of the sample mean placebo were read from the heights of the peaks that were recorded for each impurity. Based on the signal-to-noise ratio, the theoretical concentration of analyte corresponding to the triplicate noise was calculated. Then, the solutions were prepared and analysed for concentrations of impurities. The detection limit value for each of the test substances is summarised in Table 3. The limit of detection was confirmed by analysis of the solution of the six-fold concentrations of limit of detection (LOD). An example of this analysis is shown in Figure 5.

5.6. Recovery Factor. Recovery factors were calculated for every identified impurity and for the azelaic acid. Subsequently, we calculated the ratios of the recovery factor (RRF) of an identified impurity (I1-I9) to the azelaic acid (AA). 
TABLE 1: Results of the assessment of the precision of the chromatographic system due to the assessments of nine identified impurities of the azelaic acid.

\begin{tabular}{|c|c|c|c|c|c|c|c|c|c|}
\hline \multirow{2}{*}{ Measurement } & \multicolumn{9}{|c|}{ Peak area $(\mathrm{A})$ for the assessed identified impurities: $[\mathrm{mV} \times \mathrm{s}]$} \\
\hline & I1 & I 2 & I3 & I4 & I5 & I6 & I7 & I8 & I9 \\
\hline 1 & 258.113 & 1203.014 & 1706.031 & 1746.713 & 2830.966 & 2752.13 & 4702.942 & 3528.136 & 3821.195 \\
\hline 2 & 267.883 & 1201.028 & 1717.689 & 1736.138 & 2809.523 & 2760.488 & 4735.845 & 3499.348 & 3827.302 \\
\hline 3 & 269.431 & 1207.302 & 1710.66 & 1735.395 & 2805.159 & 2751.771 & 4728.282 & 3506.829 & 3831.149 \\
\hline 4 & 261.999 & 1208.041 & 1717.319 & 1757.147 & 2842.288 & 2740.871 & 4701.934 & 3511.741 & 3804.322 \\
\hline 5 & 265.122 & 1193.801 & 1715.516 & 1746.554 & 2801.162 & 2787.357 & 4698.756 & 3501.03 & 3805.952 \\
\hline 6 & 259.204 & 1204.02 & 1698.914 & 1756.218 & 2805.766 & 2754.597 & 4730.213 & 3490.329 & 3821.493 \\
\hline 7 & 266.327 & 1193.193 & 1696.215 & 1744.038 & 2824.143 & 2751.029 & 4736.137 & 3493.413 & 3844.485 \\
\hline 8 & 258.348 & 1201.998 & 1699.815 & 1743.793 & 2829.951 & 2765.384 & 4703.253 & 3532.354 & 3824.421 \\
\hline$X$ & 263.303 & 1201.550 & 1707.770 & 1745.750 & 2818.620 & 2757.953 & 4717.170 & 3507.898 & 3822.540 \\
\hline SD & 4.49 & 5.53 & 8.75 & 7.99 & 15.14 & 13.88 & 16.77 & 15.41 & 13.05 \\
\hline RSD & 1.7 & 0.5 & 0.5 & 0.5 & 0.5 & 0.5 & 0.4 & 0.4 & 0.3 \\
\hline
\end{tabular}

I1-I9: identified impurities, $X$ : average, SD: standard deviation, SRD: relative standard deviation.

TABLE 2: Results of the evaluation of the precision of the system.

\begin{tabular}{lccccc}
\hline \multicolumn{5}{c}{ Content [\%] } \\
$\begin{array}{l}\text { No. of the } \\
\text { sample }\end{array}$ & $R_{t}=24.9^{\prime}$ & $R_{t}=29.8^{\prime}$ & $R_{t}=23.1^{\prime}$ & $R_{t}=26.8^{\prime}$ & $R_{t}=31.3^{\prime}$ \\
\hline 1 & 0.03 & 0.11 & 0.09 & 0.75 & 0.16 \\
2 & 0.03 & 0.09 & 0.09 & 0.72 & 0.13 \\
3 & 0.03 & 0.13 & 0.07 & 1.01 & 0.14 \\
4 & 0.03 & 0.13 & 0.07 & 1.08 & 0.14 \\
5 & 0.03 & 0.12 & 0.06 & 0.58 & 0.13 \\
6 & 0.02 & 0.10 & 0.07 & 0.54 & 0.11 \\
7 & 0.03 & 0.11 & 0.07 & 0.63 & 0.11 \\
8 & 0.04 & 0.13 & 0.08 & 0.97 & 0.14 \\
\hline$X$ & 0.03 & 0.12 & 0.08 & 3.28 & 0.15 \\
SD & 0.03 & 0.12 & 0.08 & 1.26 & 0.14 \\
RSD & 0.005 & 0.02 & 0.01 & 1.05 & 0.02 \\
\hline
\end{tabular}

I5 and I6: identified impurities; U2, U5, U6: unidentified impurities; $R_{t}$ : retention time; $X$ : average; SD: standard deviation; and RSD: relative standard deviation.

The values in Table 3 were calculated on the basis of a single concentration, without applying the test of linearity for different impurities. As an acceptance criterion, RRF was specified within the range of $0.8-1.2$.

\section{Conclusions}

An unidentified impurity with an average retention time of $26.8 \mathrm{~min}$ appears in the samples and increases with time in the course of successive injections of the same solution, so the sample tested must be prepared immediately prior to injection. The method is selective, which makes it possible to identify the correct limit of azelaic acid impurities present in the liposomal form of azelaic acid intended for topical application. The precision of the system indicates that the chromatographic system is stable and is chosen properly. The precision of the method indicates that the results obtained
TABLE 3: LODs and RRFs for the identified impurities.

\begin{tabular}{lcccc}
\hline Impurity & \multicolumn{2}{c}{ Limit of detection } & $\mathrm{RF}$ & $\mathrm{S}\left(\mathrm{RF}_{\mathrm{I}} / \mathrm{RF}_{\mathrm{AA}}\right)$ \\
\hline $\mathrm{I} 1$ & 0.090 & 0.003 & 4203 & 0.18 \\
$\mathrm{I} 2$ & 0.009 & 0.005 & 11074 & 0.49 \\
$\mathrm{I} 3$ & 0.004 & 0.003 & 19708 & 0.87 \\
$\mathrm{I} 4$ & 0.005 & 0.005 & 33817 & 1.49 \\
$\mathrm{I} 5$ & 0.005 & 0.010 & 27914 & 1.23 \\
$\mathrm{I} 6$ & 0.004 & 0.012 & 31513 & 1.39 \\
$\mathrm{I} 7$ & 0.004 & 0.008 & 40574 & 1.79 \\
$\mathrm{I} 8$ & 0.002 & 0.004 & 38946 & 1.72 \\
$\mathrm{I} 9$ & 0.003 & 0.007 & 46134 & 2.03 \\
\hline AA & & & 22699 & - \\
\hline
\end{tabular}

RF: recovery factor, RRF: ratio of the recovery factor of an impurity $\left(\mathrm{RF}_{\mathrm{I}}\right)$ to the recovery factor of azelaic acid $\left(\mathrm{RF}_{\mathrm{AA}}\right)$, I1-I9: identified impurities, and AA: azelaic acid.

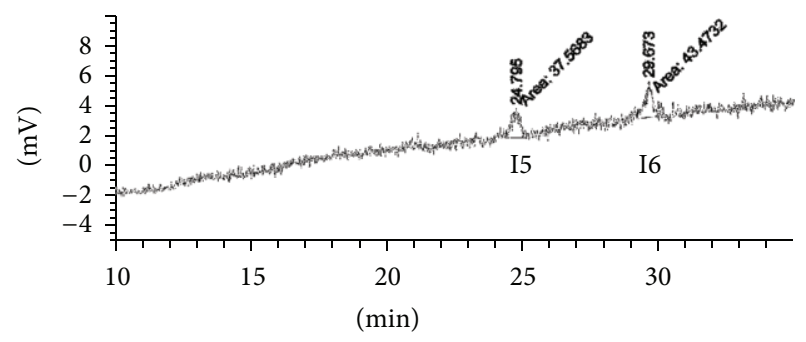

FIGURE 5: Example of the evaluation of the limits of detection, I5 and I6-identified impurities.

are highly reproducible. The limits of detection confirmed experimentally for the identified impurities I1, I2, I3, I4, I5, I6, I7, I8, and I9 were $0.090 \mathrm{mg} / \mathrm{mL}, 0.009 \mathrm{mg} / \mathrm{mL}, 0.004 \mathrm{mg} / \mathrm{mL}$, $0.005 \mathrm{mg} / \mathrm{mL}, \quad 0.005 \mathrm{mg} / \mathrm{mL}, \quad 0.004 \mathrm{mg} / \mathrm{mL}, 0.004 \mathrm{mg} / \mathrm{mL}$, $0.002 \mathrm{mg} / \mathrm{mL}$, and $0.003 \mathrm{mg} / \mathrm{mL}$, respectively. This statistical method meets the statistical requirements for pharmaceutical products and provides an analytical method for determining 
the limit of azelaic acid impurities in the tested liposomal formulation of azelaic acid.

\section{Acknowledgments}

This paper was cofinanced by Wrocław Research Center EIT+ within the framework of the European Social Fund, project no. POKL.08.02.01-02-011/11.

\section{References}

[1] P. T. Bladon, B. M. Burke, and W. J. Cunliffe, "Topical azelaic acid and the treatment of acne: a clinical and laboratory comparison with oral tetracycline," British Journal of Dermatology, vol. 114, no. 4, pp. 493-499, 1986.

[2] D. Stamatiadis, M.-C. Bulteau-Portois, and I. Mowszowicz, "Inhibition of $5 \alpha$-reductase activity in human skin by zinc and azelaic acid," British Journal of Dermatology, vol. 119, no. 5, pp. 627-632, 1988.

[3] D. Thiboutot, G. Harris, V. Iles, G. Cimis, K. Gilliland, and S. Hagari, "Activity of the type $15 \alpha$-reductase exhibits regional differences in isolated sebaceous glands and whole skin," Journal of Investigative Dermatology, vol. 105, no. 2, pp. 209-214, 1995.

[4] M. L. Buch, R. Montgomery, and W. L. Porter, "Identification of organic acids on paper chromatograms," Analytical Chemistry, vol. 24, no. 3, pp. 489-491, 1952.

[5] T. Higuchi, N. C. Hill, and G. B. Corcoran, "Chromatographic separation and determination of dicarboxylic acids, C4 to C10," Analytical Chemistry, vol. 24, no. 3, pp. 491-493, 1952.

[6] L. D. Metcalfe and A. A. Schmitz, "The rapid preparation of fatty acid esters for gas chromatographic analysis," Analytical Chemistry, vol. 33, no. 3, pp. 363-364, 1961.

[7] M. R. Schilling, R. Michael, and H. P. Khanjian, "Gas chromatographic determination of the fatty acid and glycerol content of lipids: I. The effects of pigments and aging on the composition of oil paints," in Proceedings of the ICOM Committee for Conservation, 11th Triennial Meeting in Edinburgh, Scotland, pp. 220-227, James \& James Science, London, UK, 1996.

[8] M. P. Colombini, F. Modugno, M. Giacomelli, and S. Francesconi, "Characterisation of proteinaceous binders and drying oils in wall painting samples by gas chromatographymass spectrometry," Journal of Chromatography A, vol. 846, no. 1-2, pp. 113-124, 1999.

[9] M. P. Colombini, F. Modugno, E. Menicagli, R. Fuoco, and A. Giacomelli, "GC-MS characterization of proteinaceous and lipid binders in UV aged polychrome artifacts," Microchemical Journal, vol. 67, no. 1-3, pp. 291-300, 2000.

[10] Y. Yokouchi and Y. Ambe, "Characterization of polar organics in airborne particulate matter," Atmospheric Environment, vol. 20, no. 9, pp. 1727-1734, 1986.

[11] K. Kawamura and T. Watanabe, "Determination of stable carbon isotopic compositions of low molecular weight dicarboxylic acids and ketocarboxylic acids in atmospheric aerosol and snow samples," Analytical Chemistry, vol. 76, no. 19, pp. 5762-5768, 2004.

[12] E. Pusvaskiene, B. Januskevic, A. Prichodko, and V. Vickackaite, "Simultaneous derivatization and dispersive liquid-liquid microextraction for fatty acid GC determination in water," Chromatographia, vol. 69, no. 3-4, pp. 271-276, 2009.

[13] C. D. Cappa, E. R. Lovejoy, and A. R. Ravishankara, "Determination of evaporation rates and vapor pressures of very low volatility compounds: a study of the C4-C10 and $\mathrm{C} 12$ dicarboxylic acids," Journal of Physical Chemistry A, vol. 111, no. 16, pp. 3099-3109, 2007.

[14] T. J. Clark and J. E. Bunch, "Derivatization solid-phase microextraction gas chromatographic-mass spectrometric determination of organic acids in Tobacco," Journal of Chromatographic Science, vol. 35, no. 5, pp. 209-212, 1997.

[15] F. Levai, C.-M. Liu, M. M. Tse, and E. T. Lin, "Pre-column fluorescence derivatization using leucine-coumarnylamide for HPLC determination of mono- and dicarboxylic acids in plasma," Acta Physiologica Hungarica, vol. 83, no. 1, pp. 39-46, 1995.

[16] J. E. Pettersen, E. Jeelum, and L. Eedjarn, "The occurrence of adipic and suberic acid in urine from ketotic patients," Clinica Chimica Acta, vol. 38, no. 1, pp. 17-24, 1972.

[17] A. M. Mansour and M. M. Ibrahiem, "Simultaneous determination of azelaic and benzoic acids in topical preparations by liquid chromatography," Chromatographia, vol. 55, no. 7-8, pp. 435-437, 2002.

[18] V. Ferioli, C. Rustichelli, F. Vezzalini, and G. Gamberini, "Determination of azelaic acid in pharmaceuticals and cosmetics by RP-HPLC after pre-column derivatization," Farmaco, vol. 49, no. 6, pp. 421-425, 1994.

[19] R. Gatti, V. Andrisano, A. M. Di Pietra, and V. Cavrini, "Analysis of aliphatic dicarboxylic acids in pharmaceuticals and cosmetics by liquid chromatography (HPLC) wih fluorescence detection," Journal of Pharmaceutical and Biomedical Analysis, vol. 13, no. 4-5, pp. 589-595, 1995.

[20] T. G. Sobolevsky, A. I. Revelsky, I. A. Revelsky, B. Miller, and V. Oriedo, "Simultaneous determination of fatty, dicarboxylic and amino acids based on derivatization with isobutyl chloroformate followed by gas chromatography-positive ion chemical ionization mass spectrometry," Journal of Chromatography B, vol. 800, no. 1-2, pp. 101-107, 2004.

[21] E. Bravi, G. Perretti, and L. Montanari, "Fatty acids by highperformance liquid chromatography and evaporative lightscattering detector," Journal of Chromatography A, vol. 1134, no. 1-2, pp. 210-214, 2006.

[22] J. Zhao, S. P. Li, F. Q. Yang, P. Li, and Y. T. Wang, "Simultaneous determination of saponins and fatty acids in Ziziphus jujuba (Suanzaoren) by high performance liquid chromatographyevaporative light scattering detection and pressurized liquid extraction," Journal of Chromatography A, vol. 1108, no. 2, pp. 188-194, 2006.

[23] Y. Wei and M. Y. Ding, "The evaporative light-scattering detection technology," Se Pu, vol. 18, no. 5, pp. 398-401, 2000.

[24] G. K. Webster, J. S. Jensen, and A. R. Diaz, "An investigation into detector limitations using evaporative light-scattering detectors for pharmaceutical applications," Journal of Chromatographic Science, vol. 42, no. 9, pp. 484-490, 2004.

[25] H. E. Fries, C. A. Evans, and K. W. Ward, "Evaluation of evaporative light-scattering detection for metabolite quantification without authentic analytical standards or radiolabel," Journal of Chromatography B, vol. 819, no. 2, pp. 339-344, 2005.

[26] T. A. Foglia and K. C. Jones, "Quantitation of neutral lipid mixtures using high performance liquid chromatography with light scattering detection," Journal of Liquid Chromatography and Related Technologies, vol. 20, no. 12, pp. 1829-1838, 1997.

[27] A. I. Hopia and V.-M. Ollilainen, "Comparison of the evaporative light scattering detector (ELSD) and refractive index detector (RID) in lipid analysis," Journal of Liquid Chromatography, vol. 16, no. 12, pp. 2469-2482, 1993. 
[28] F. M. Wurst, S. Alexson, M. Wolfersdorf et al., "Concentration of fatty acid ethyl esters in hair of alcoholics: comparison to other biological state markers and self reported-ethanol intake," Alcohol and Alcoholism, vol. 39, no. 1, pp. 33-38, 2004.

[29] T. Seppänen-Laakso, I. Laakso, H. Vanhanen, K. Kiviranta, T. Lehtimäki, and R. Hiltunen, "Major human plasma lipid classes determined by quantitative high-performance liquid chromatography, their variation and associations with phospholipid fatty acids," Journal of Chromatography B, vol. 754, no. 2, pp. 437-445, 2001.

[30] C. Lopez, V. Briard-Bion, O. Menard, F. Rousseau, P. Pradel, and J.-M. Besle, "Phospholipid, sphingolipid, and fatty acid compositions of the milk fat globule membrane are modified by diet," Journal of Agricultural and Food Chemistry, vol. 56, no. 13, pp. 5226-5236, 2008.

[31] Q2(R1) CPMP/ICH/381/95 "Validation of Analytical Procedures: Text \& Methodology".

[32] United States Food and Drug Administration, Guideline for Submitting Samples and Analytical Data for Methods Validation, Rockville, Md, USA, 1987.

[33] Association of Analytical Communities International, Peer Verified Methods Program, Manual on Policies and Procedures, Fisher Lane, Arlington, Va, USA, 1993. 

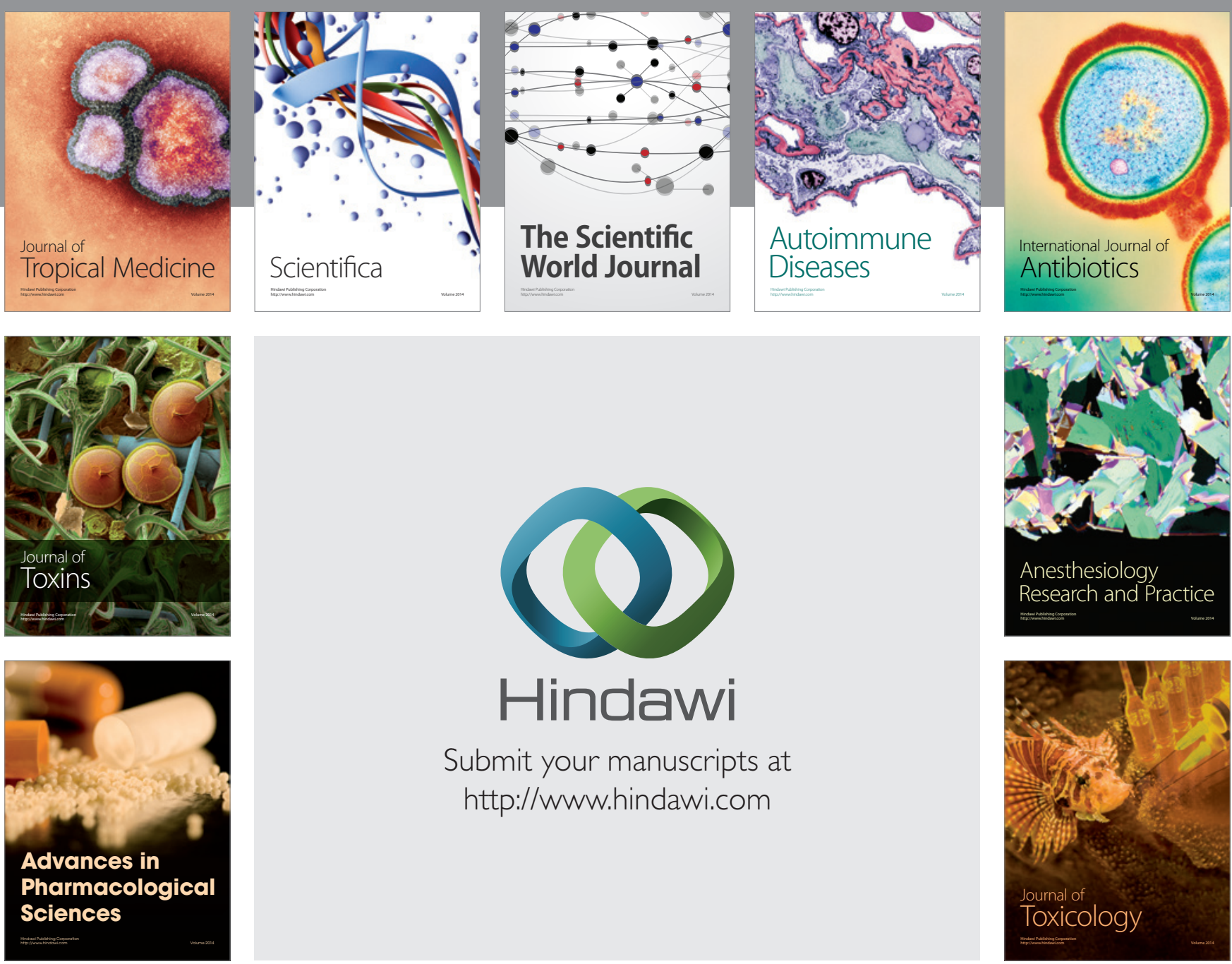

\section{Hindawi}

Submit your manuscripts at

http://www.hindawi.com
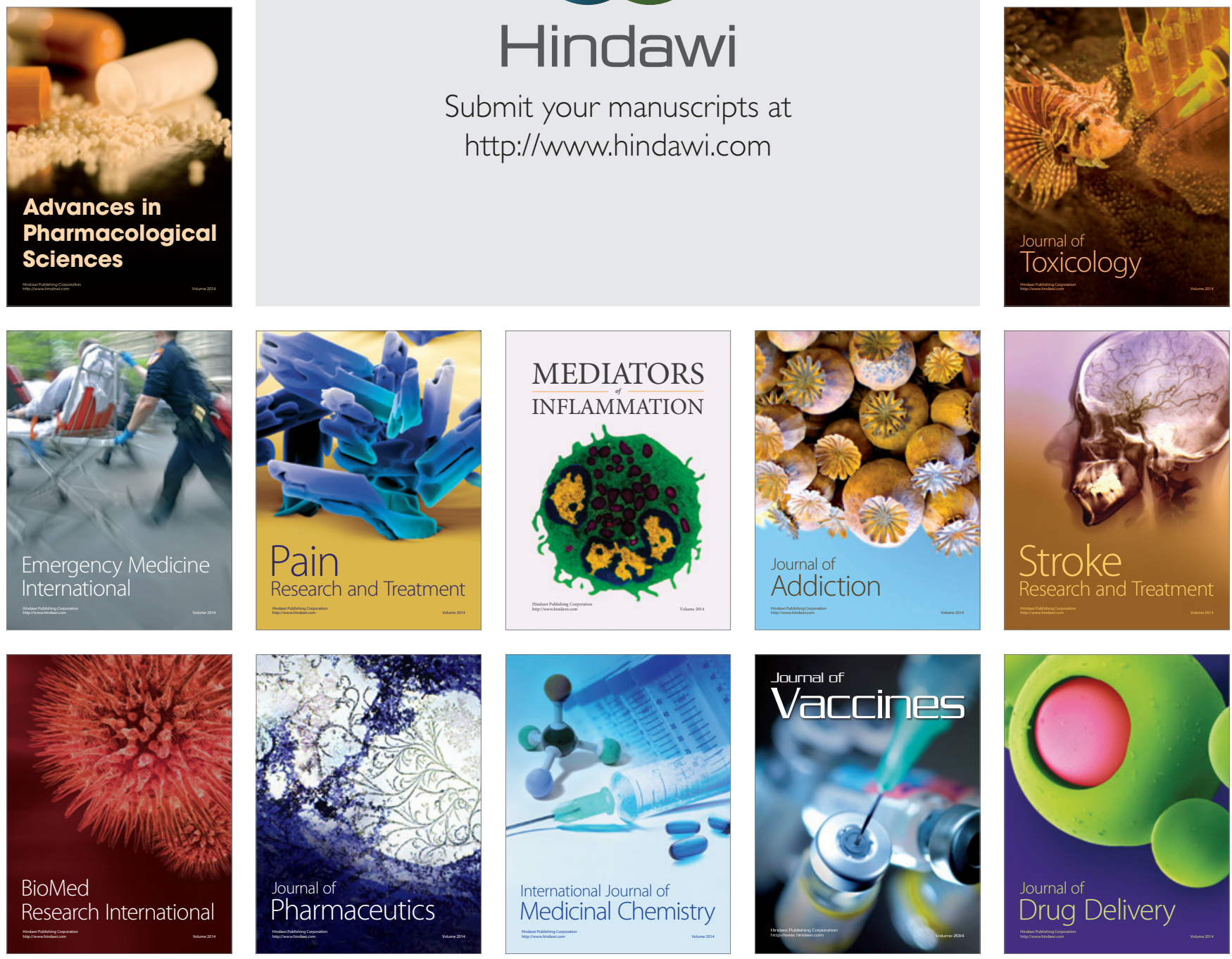